Article

\title{
Friction and Wear Pattern of Silica-Reinforced Styrene-Butadiene Rubber (SBR) in Sliding Contact with a Blade Indenter
}

\author{
Budi Setiyana ${ }^{1,2}$, Muhammad Khafidh ${ }^{3}\left(\mathbb{D}\right.$, Mohammad Tauviqirrahman ${ }^{2, *}$, Rifky Ismail ${ }^{2}$, Jamari ${ }^{2}$ (D) and \\ Dirk Jan Schipper ${ }^{1}$ D
}

1 Faculty of Engineering Technology, University of Twente, P.O. Box 217, 7500 AE Enschede, The Netherlands; bsetiyana@yahoo.com (B.S.); d.j.schipper@utwente.nl (D.J.S.)

2 Mechanical Engineering Department, University of Diponegoro, Jl. Prof. Soedharto SH, Tembalang, Semarang 50275, Indonesia; rifky_ismail@ft.undip.ac.id (R.I.); j.jamari@gmail.com (J.)

3 Mechanical Engineering Department, Islamic University of Indonesia, Jl. Kaliurang Km 14.5, Yogyakarta 55584, Indonesia; khafidh@uii.ac.id

* Correspondence: mohammad.tauviqirrahman@ft.undip.ac.id

check for updates

Citation: Setiyana, B.; Khafidh, M.; Tauviqirrahman, M.; Ismail, R.; Jamari; Schipper, D.J. Friction and Wear Pattern of Silica-Reinforced Styrene-Butadiene Rubber (SBR) in Sliding Contact with a Blade Indenter. Lubricants 2021, 9, 110. https:/ / doi.org/10.3390/lubricants9110110

Received: 3 October 2021

Accepted: 12 November 2021

Published: 17 November 2021

Publisher's Note: MDPI stays neutral with regard to jurisdictional claims in published maps and institutional affiliations.

Copyright: (c) 2021 by the authors. Licensee MDPI, Basel, Switzerland. This article is an open access article distributed under the terms and conditions of the Creative Commons Attribution (CC BY) license (https:/ / creativecommons.org/licenses/by/ $4.0 /)$.

\begin{abstract}
This study investigated the friction and wear pattern of silica-reinforced Styrene-Butadiene Rubber (SBR) in sliding friction with a steel blade indenter. The experiments were conducted using a pin-on-disc tribometer at various applied loads and examined under dry and wet contact conditions. Analysis was focused on investigating the coefficient of friction and length of wear pattern spacing. Related to coefficient of friction identification, the abrasion theory was applied here. In addition, the stick-slip theory to identify the wear pattern spacing was also applied. Results of the experiments show that the overall coefficient of friction (COF) decreases along with the increasing applied loads. The COF in wet conditions is much lower at the beginning of sliding time than the COF in dry conditions. The wear pattern spacing increases with increasing loads. However, it seems that there is no significant difference in pattern spacing between the dry and wet contact condition. In general, the experimental results agree qualitatively with the analytical results.
\end{abstract}

Keywords: rubber abrasion; sliding friction; stick-slip; wear pattern

\section{Introduction}

Friction or abrasion phenomena of a rubber surface in contact with a counter surface are still difficult to discuss analytically using a multi asperity contact approach. Therefore, an analytical or numerical approach is often started using a single asperity as a counter surface. In metals, volume loss and wear mode from abrasion by a rigid sharp cone has been presented experimentally and analytically [1], but volume loss did not occur in practice in rubber abrasion [2,3]. Because of this, some researchers have not shown a particular interest in investigating rubber abrasion by a point contact. However, some researchers have investigated rubber abrasion based on a line-contact using a blade indenter as a single asperity. In addition to producing volume loss, wear pattern on an abraded rubber surfaces closely resembles the abrasion pattern in general cases of rubber abrasion [4]. Accordingly, the tribological system of the line-contact abrasion has been studied frequently [5-12].

Generally, most of the experimental results with the blade indenter are to identify the abrasion mechanism, wear rate and crack growth during abrasion. There are several parameters related to those experiment such as the effect of load, temperature, tensile strength, sharpness of the indenter and environmental conditions (dry or wet). However, only a few of them put forward the concept or theory of rubber abrasion $[7,13,14]$. In general, the abrasion contact theory consists of sliding contact and wear contact. Theory of the sliding contact between two surfaces was proposed by Persson and Basse with assumption that the contour of the contact surface may be fluctuating or wavy $[15,16]$. 
Theory of wear contact is separated between sharp and blunt indenters. Contact with the sharp indenter or asperity causes rupturing on the rubber surface, on the other hand, contact with a blunt indenter requires repeated contact to cause rupturing, which is known as fatigue wear [17]. Theory of abrasion in the form of point contact such as between a sharp asperity and a rubber surface was proposed by Moore $[18,19]$. Regarding the Moore's theory, abrasion contact consists of two components: the sliding and rupturing components $[18,19]$. The sliding component corresponds to the micro-molecular force generated at the interface between the rubber and its counter surface, while the rupturing component corresponds to the macro mechanical force impacted on the rubber surface by the counter surface. The sliding contact consists of adhesion and elastic (deformation) components, which depend on the surface's roughness and elasticity, while the rupturing component depends on the breaking strength of the molecular chain. The sliding and rupturing mechanism commonly occurs as a stick-slip phenomenon that is usually found in rubber abrasion [3-11]. Due to the stick-slip occurrence, the fluctuating friction force is usually obtained, and a periodic wear pattern is produced.

Identification of the wear pattern spacing has also been theorized as a stick-slip theory that the length of the pattern spacing does not only depend on the static load on the indenter but also depends on dynamic load due to the oscillating motion of the indenter and its frame along abrasion. Based on the formula, this stick-slip theory is applicable to various types of indenter tip [20,21]. Experimentally, it has also been shown that there is a correlation between pattern spacing length and abrasion rate $[9,22]$.

Based on the above discussion, this research studied the tribological responses of rubber abrasion using a sharp blade indenter. It was performed with considering that the line-contact abrasion is assumed as a row of point contacts. The Moore and stick-slip theory mentioned above were applied here. Moore's theory was applied to find out its validity for the line-contact abrasion while the stick-slip theory was applied to find out its validity for the blade type of indenter tip. The rubber material used as a testing specimen was reinforced Styrene-Butadiene Rubber. The experiment was carried out using a pin-on-disc tester with various given indenter loads. In addition, the testing specimen was examined in dry and wetted contact conditions. The coefficient of friction (COF) and wear pattern of abraded rubber surface were analyzed experimentally. However, the volume loss is not discussed here.

\section{Materials and Methods}

\subsection{Materials}

The rubber used in the present study was a Styrene-Butadiene Rubber (SBR) and a high-cis-polybutadiene (BR) reinforced by $80 \mathrm{phr}$ (parts per hundred rubber) of highly dispersible silica. The coupling agent bis-(tri-ethoxy-silyl propyl) tetrasulfide (TESPT) was used to provide sufficient interaction between the silica particles and the rubber matrix. The formulation of the rubber is based on a silica-reinforced passenger car tyre tread called "green tyre" [23]. The details of the formulation in parts per hundred rubber (phr) are given in Table 1.

The materials were mixed in a Brabender $350 \mathrm{~S}$ (Brabender ${ }^{\circledR} \mathrm{GmbH} \& \mathrm{Co}$. KG, Duisburg, Germany) internal mixer. The materials were then vulcanized in a Wickert press WLP 1600 at 100 bar and $160^{\circ} \mathrm{C}$, according to their 190 min optimum vulcanization times, as determined by a Rubber Process Analyzer (RPA 2000) of Alpha Technologies (John F Kennedylaan 2, 5612 AB Eindhoven, The Netherland), following the procedure described in ISO standard 3417. Vulcanized rubbers with $2 \mathrm{~mm}$ thickness were prepared for the tensile tests, while vulcanized rubbers with $5 \mathrm{~mm}$ thickness were prepared for tribometer tests. 
Table 1. Formulation of the rubber materials.

\begin{tabular}{ccc}
\hline Ingredients & [in phr] & Supplier \\
\hline SBR & 97.3 & Arlanxeo, Leverkusen, Germany \\
BR & 30.0 & Kumho, Seoul, Korea \\
Silica & 80.0 & Evonik Industries AG, Essen, Germany \\
Zinc oxide (ZnO) & 2.5 & Sigma Aldrich, St. Louis, MI, USA \\
Stearic acid (SA) & 2.5 & Sigma Aldrich, St. Louis, MI, USA \\
Treated Distillate Aromatic Extract & 6.7 & Hansen \& Rosenthal, Hamburg, Germany \\
(TDAE) & 7.0 & Evonik Industries AG, Essen, Germany \\
TESPT & 2.0 & Flexsys, Brussels, Belgium \\
6PPD & 2.0 & Flexsys, Brussels, Belgium \\
TMQ & 1.4 & Sigma Aldrich, St. Louis, MI, USA \\
Sulfur & 1.7 & Flexsys, Brussels, Belgium \\
N-Cyclohexyl Benzothiazole & 2.0 & Flexsys, Brussels, Belgium \\
Sulfenamide (CBS) &
\end{tabular}

Mechanical properties are important in terms of describing the tribological behavior of the material. Regarding material strength, tensile tests were performed using an Intron tensile tester with a load cell of $1000 \mathrm{~N}$, according to ISO 37 at a crosshead velocity of $500 \mathrm{~mm} / \mathrm{min}$ Based on the experimental results, the elastic modulus of the material is $4.8 \pm 0.2 \mathrm{MPa}$ with estimated tensile strength of $20 \mathrm{MPa}$. In this case, the elastic modulus is defined at a strain of $2 \%$, assuming that the material behaves linearly at such strain [24].

\subsection{Methods}

A schematic of the pin-on-disc tribometer and blade indenter used in the current study is presented in Figure 1a,b. It consists of a rotating rubber specimen in contact with an indenter system. The indenter system consists of the blade indenter itself, deadweight, beam, and counterweight. To obtain a good sliding contact, the width of blade indenter is made larger than the contact width. The rubber specimens were prepared as a disc with circular contact width of $5 \mathrm{~mm}$ and outside diameter of $26.5 \mathrm{~mm}$. The counter surface used was a straight blade indenter with a specified wedge angle and tip width. In the present study, the sharp blade indenter was made of steel with a wedge angle of $16^{\circ}$ and a width of $13 \mathrm{~mm}$. The indenter tip was made as sharp as possible. It was rather difficult to measure the tip radius whose value can vary along the width of the indenter tip. The estimated tip radius value is about 0.5 to $0.8 \mathrm{~mm}$. The photographs of the specimen and blade indenter are depicted in Figure 1c,d.

The dry tests were performed at $5 \mathrm{~cm} / \mathrm{s}$ constant sliding velocity, $24 \mathrm{~mm}$ track radius and different applied loads, namely $1.0 \mathrm{~N}, 1.5 \mathrm{~N}$ and $2.0 \mathrm{~N}$. The low sliding velocity $(5 \mathrm{~cm} / \mathrm{s})$ was selected to avoid high normal oscillation of the blade indenter. This is because of the high attack angle of blade tip which tends to make the indenter move vertically when it contacts a crack at the surface. An additional wet test was conducted at an applied load of $1.0 \mathrm{~N}$ to investigate the effect of adhesion between the contacting materials. The rubber surface was wetted with a very thin layer of low-viscosity oil (Ondina 927 with $78 \mathrm{mPas}$ dynamic viscosity at $20^{\circ} \mathrm{C}$ ) so that the lubricated tribo-system remains in the boundary lubricated regime. After the test, the wear surfaces of the rubber were analyzed using a Keyence VHX-5000 (Keyence Corporation of America, Elmwood Park, NJ, USA) microscope with magnification capability up to 19,000 times and pixel pitch of $0.2652 \mathrm{~mm} \times 0.2652 \mathrm{~mm}$. The experimental observation is focused on the coefficient of friction and the wear pattern. 


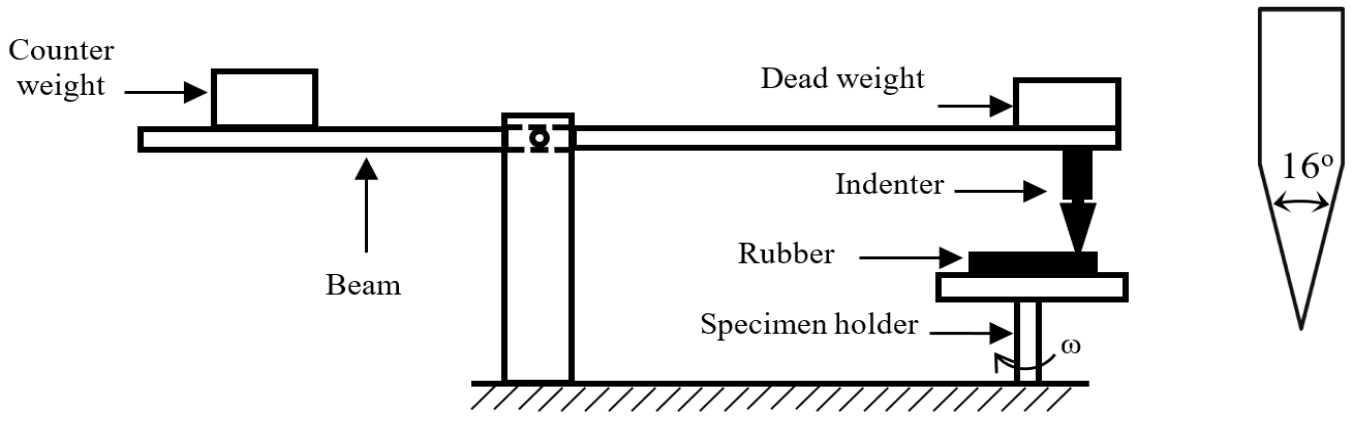

(a)

(b)

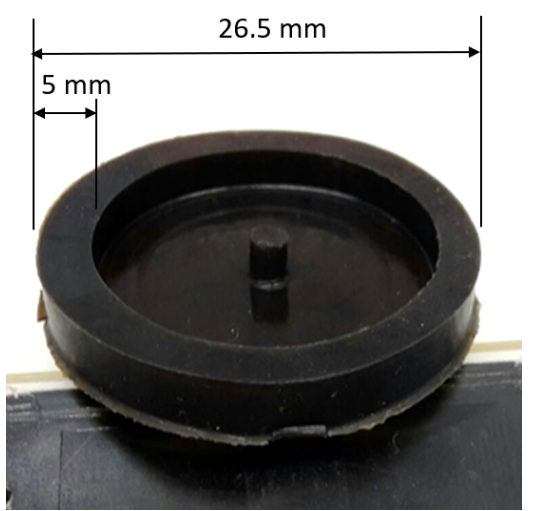

(c)

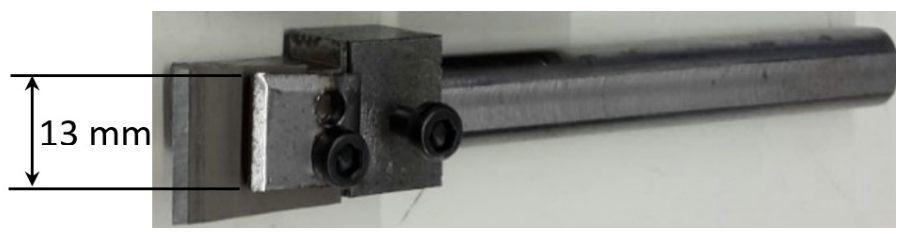

(d)

Figure 1. (a) A schematic of pin-on-disc tribometer, (b) a schematic of blade indenter, (c) photograph of specimen and (d) photograph of blade indenter.

\section{Results and Discussion}

\subsection{Experimental Results}

The experimental results of the tribometer tests for the coefficient of friction are given in Figure 2. This is a comparison example of the coefficient of friction data at the beginning of the first cycle (a) and at the beginning of the 1500th cycle (b). Furthermore, the data were taken in a short span of time that around $0.3 \mathrm{~s}$ and for only 0.1 of the cycle (around $15 \mathrm{~mm}$ length of track). The black dots are the sampling data from measurement which was then connected as a smooth line. It can be observed that the first cycle produces higher fluctuating values for the COF than at the beginning of the 1500th cycle for the different loads, $1.0 \mathrm{~N}, 1.5 \mathrm{~N}$ and $2.0 \mathrm{~N}$.

The measured coefficient of friction is presented in Figure 3 from the start to the end of the abrasion test for about $6000 \mathrm{~s}$ or about 2000 cycles. The average coefficient of friction for the different applied loads are plotted in Figure 3a. It shows that the coefficient of friction decreases as the applied load increases, particularly for long sliding times. However, there is no significant difference in the coefficient of friction found at the beginning of the sliding time. Figure $3 b$ indicates that the coefficient of friction of the wetted or lubricated surface is lower than that of the dry surface. Moreover, it reduces the COF greatly in comparison with the dry surface at the beginning of the sliding time. 


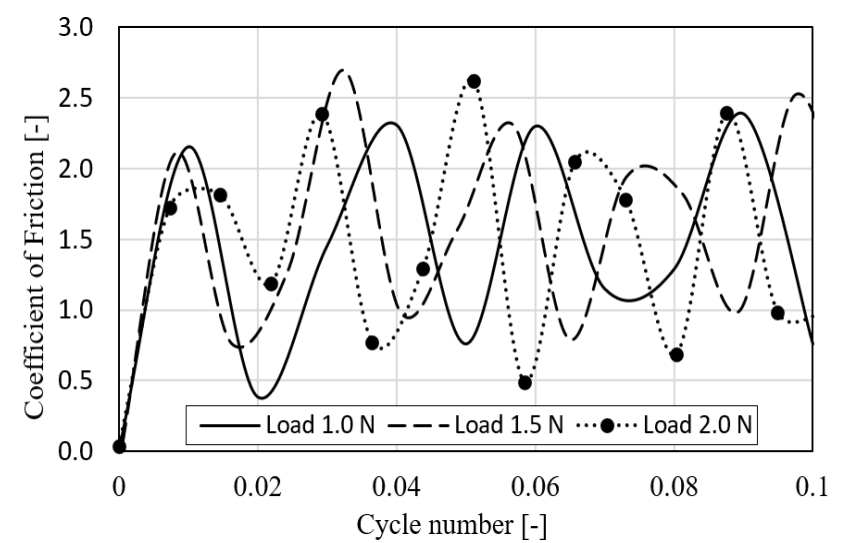

(a)

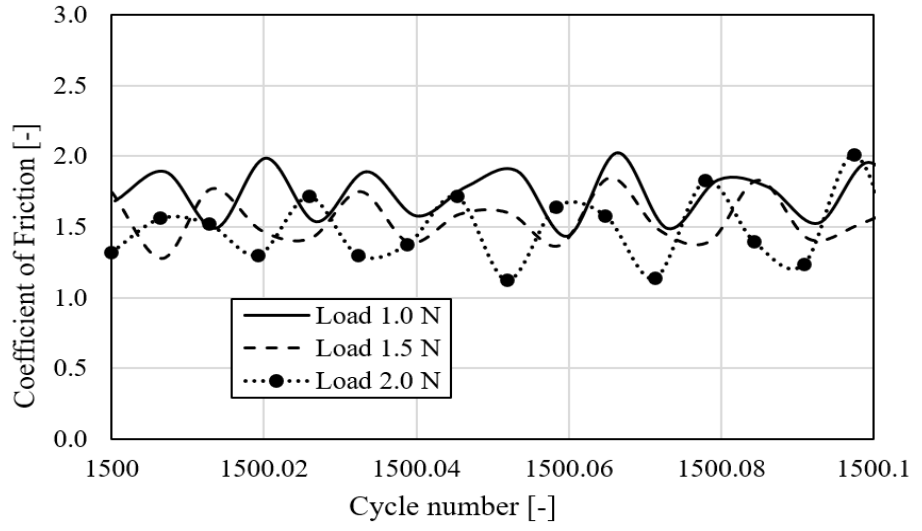

(b)

Figure 2. Coefficient of friction in a short span of time (a) at the beginning of the first cycle and (b) at the beginning of the 1500th cycle.

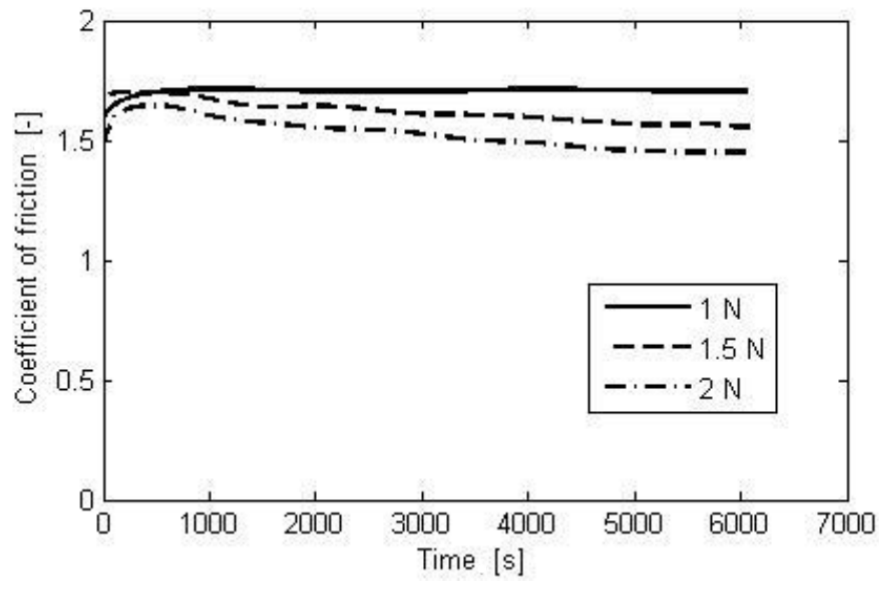

(a)

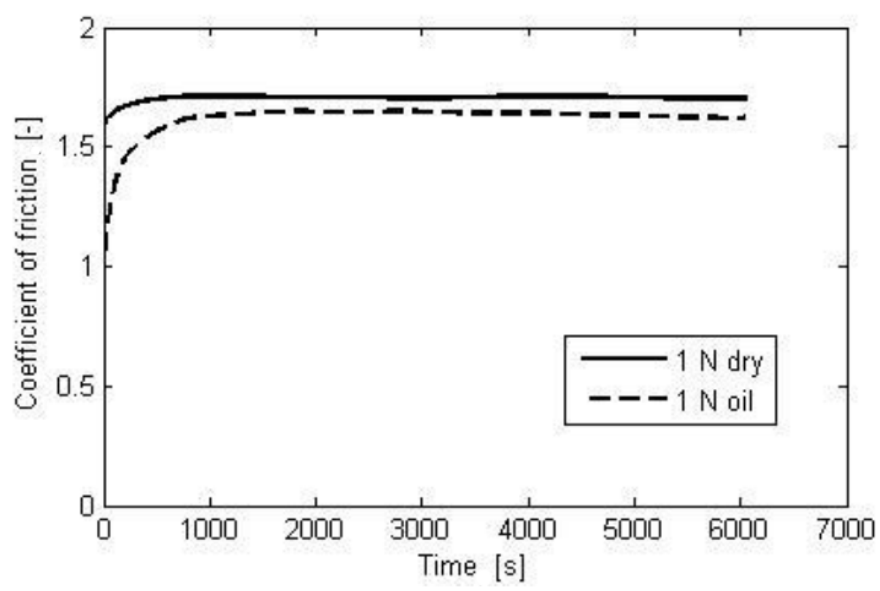

(b)

Figure 3. The coefficient of friction (COF) as a function of sliding time: (a) for various applied loads, (b) for the dry and wetted surface.

The obtained wear pattern of the abraded rubber on the dry surface can be seen in Figure 4. In general, the length of the wear pattern spacing increases along with the applied loads. Based on these figures, it can be estimated that the spacing length of wear pattern for the applied loads of $1.0 \mathrm{~N}, 1.5 \mathrm{~N}$ and $2.0 \mathrm{~N}$ are approximately $65-100 \mu \mathrm{m}, 85-115 \mu \mathrm{m}$ and 100-130 $\mu \mathrm{m}$, respectively.

Figure 5 shows the wear pattern of a wetted abraded surface with an applied load of $1.0 \mathrm{~N}$. In general, there is no significant difference between the pattern spacing of the dry surface and that of the wetted surface. 


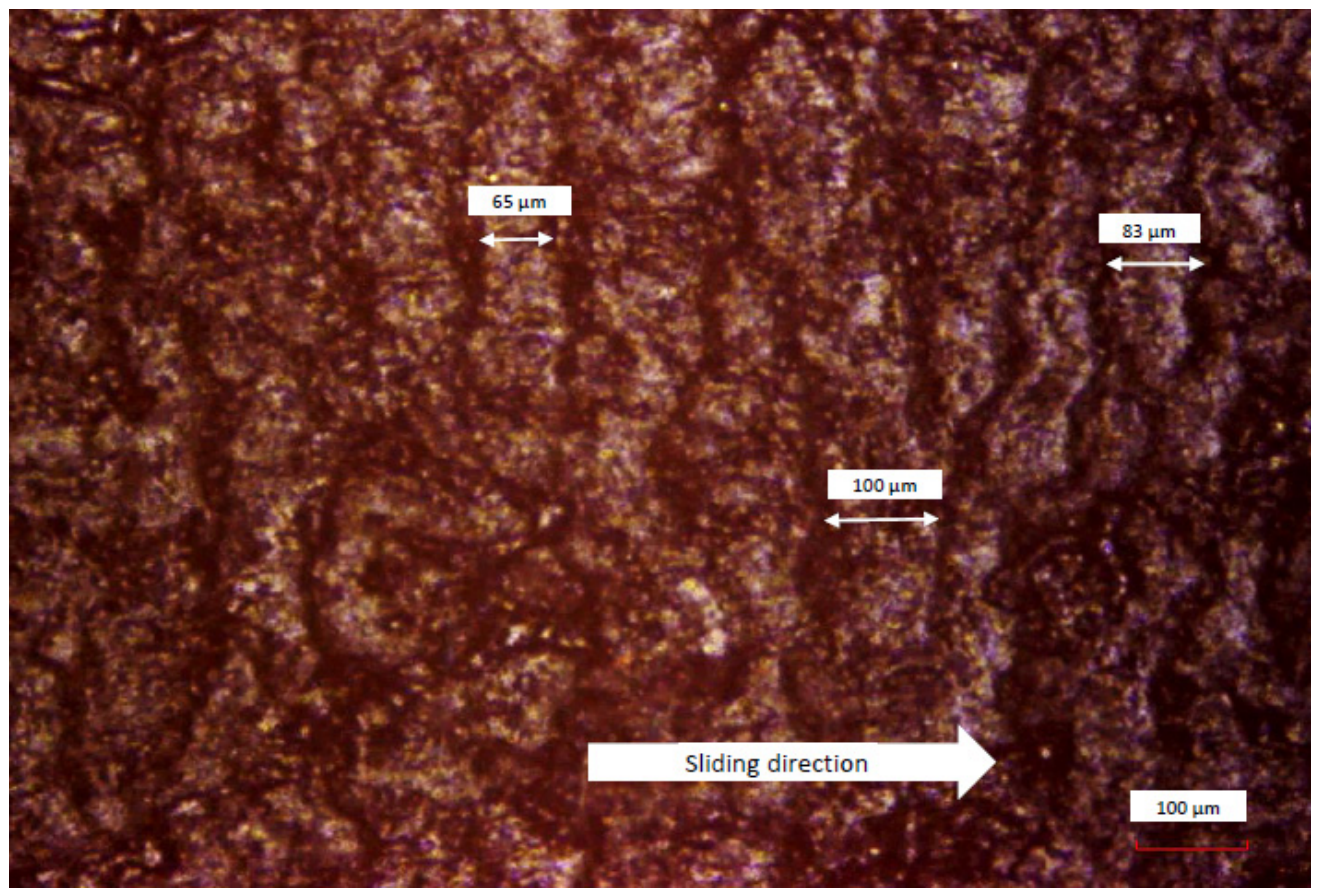

(a)

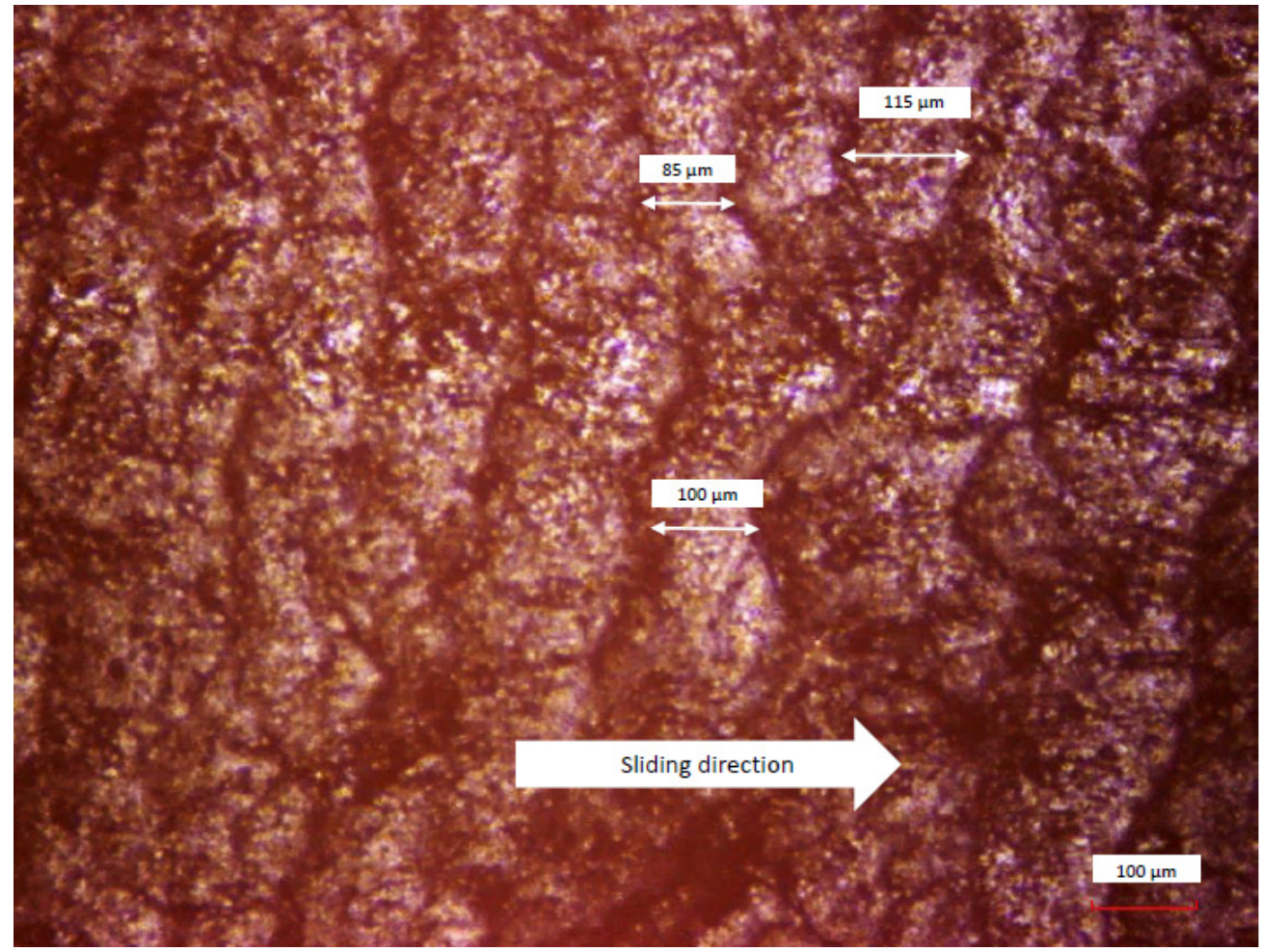

(b)

Figure 4. Cont. 


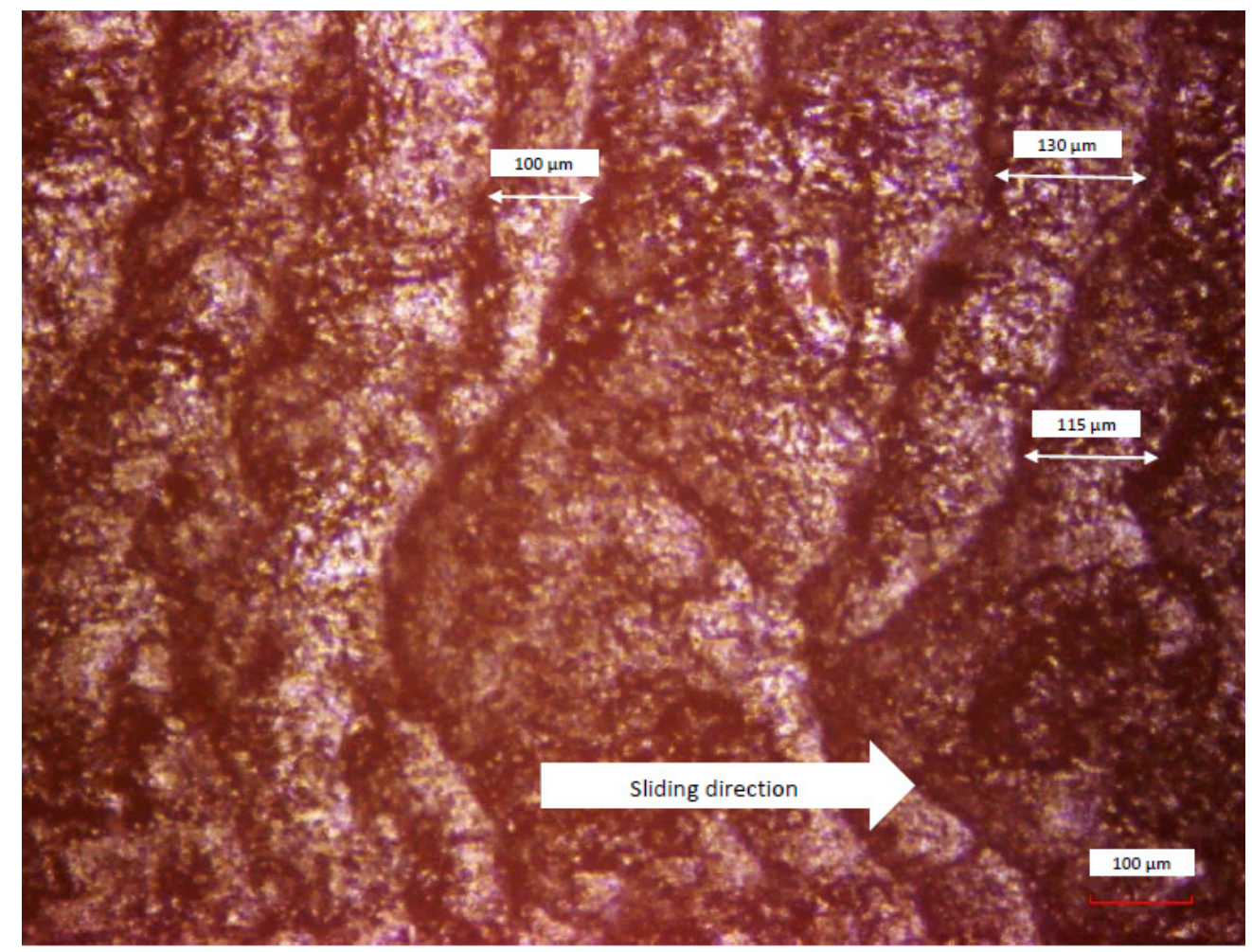

(c)

Figure 4. The wear pattern of the abraded rubber surface on dry surface. (a) Load of 1.0 $\mathrm{N}$; (b) Load of $1.5 \mathrm{~N}$; (c) Load of $2.0 \mathrm{~N}$.

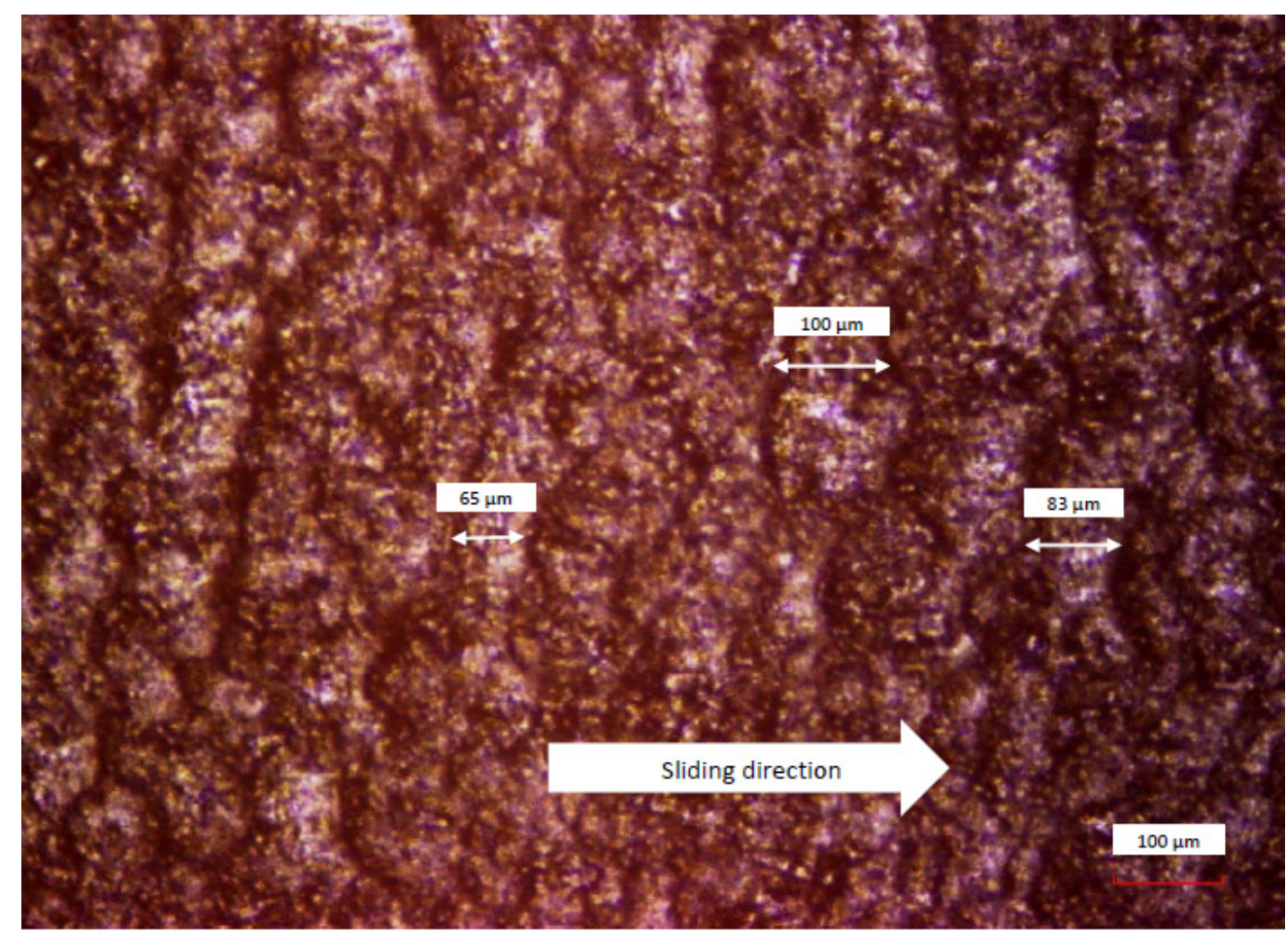

Figure 5. The wear pattern on the wetted surface, $1.0 \mathrm{~N}$ load.

\subsection{Coefficient of Friction Analysis}

In relation to the coefficient of friction in Figure 2, there is a significant difference for the beginning of the first cycle and the 1500th cycle. In Figure 2a, the fluctuation is large, 
and the oscillation frequency tends to be greater for a larger indenter load. The rubber surface condition is still smooth and indented at sliding velocity, i.e., $5 \mathrm{~cm} / \mathrm{s}$. In this case, the tangential oscillation of the stick-slip contact is more dominant than in the normal direction, therefore the tangential forces also fluctuate greatly $[12,25]$. This case is similar to a sliding indentation with a fixed depth mode. The larger the indenter load, the larger the indentation depth and the deformation; as a result, the tangential stiffness will be higher. Consequently, the oscillation frequency will also be greater. This is different from Figure $2 b$ where the surface condition of the rubber is already abraded and no longer smooth. The tip of the indenter crashes into the jagged walls of the abraded surface so that the indenter tends to oscillate in normal direction rather than in tangential direction. This happens because the stiffness in the normal direction is lower than in the tangential direction [12]. The stick-slip contact occurs as normal oscillation rather than tangential oscillation. In this condition, the larger the indenter load is, the smaller the oscillation frequency will be, as shown in Figure 2b [26].

The data from the experimental results in Figure 3 can be explained by understanding the analysis of the abrasion mechanism. In addition, the energy balancing theory is applied to the abrasion mechanism. It states that the work due to wear friction is the absorbed energy due to sliding and rupturing of the rubber material $[18,19]$. The sliding component consists of the adhesion and elastic stress (deformation) components. Then, the sliding process is more dominant in the slip phase. In this case, the indenter tip relatively moves with respect to the rubber surface and then generates an adhesive and elastic stress. Once the adhesive and elastic stress exceed the maximum stress $\sigma_{\max }$, the surface contact will be sheared or released. At that moment, the part of the rubber that has been stretched relaxes immediately. At the same time, the indenter tip continues shearing or moves forward to generate adhesive and elastic stress.

The rupturing process is more dominant in the stick phase. Under the action of normal load $F_{n}$, the indenter inserts into the rubber surface. Although relative motion occurs under the action of the tangential force, the molecular chain of rubber is stretched in the direction of movement. Once the stretching stress exceeds the breaking strength of the molecular chain of rubber $\sigma_{\text {rup }}$, the molecular chain is ruptured and then the contact is released until it forms a new stick contact.

Based on the above assumption, Moore proposed the friction coefficient due to a point contact $\mu_{\text {point }}$ using a needle or sharp cone as a single asperity [19], as seen in this following formula:

$$
\mu_{\text {point }}=\mu_{\text {slid }}+\mu_{\text {rup }}=K_{1} \frac{\sigma_{\max } \tan \delta}{H}+K_{2} \frac{\sigma_{r u p} \tan \delta}{\sqrt{F_{n} \tan \frac{\theta}{2}}}
$$

where $\mu_{\text {slid }}$ corresponds to the coefficient of friction caused by sliding, $\mu_{r u p}$ is the coefficient of friction caused by rupturing, $K_{1}$ and $K_{2}$ are constants, $\sigma_{\max }$ is the maximum shear and elastic stress, $\sigma_{\text {rup }}$ is the maximum breaking stress of the rubber chain, $\tan \delta$ is the loss factor (depend on the rubber properties), $H$ is the rubber hardness, $F_{n}$ is the applied normal load and $\theta$ is the apex angle of cone or needle tip.

In abrasion tests on a virgin specimen of rubber, the rubber surface is still smooth in the beginning of the sliding time, while at a long sliding time or frequent numbers of sliding cycles the surface becomes rough. Accordingly, the beginning of the sliding abrasion dominantly occurs in the sliding process rather than in the rupturing process and vice versa for a long sliding time [12]. As for the blade indenter or razor blade as counter-face, the sliding abrasion contact in this case can be identified as a line-contact abrasion. If the line-contact can be assumed to be a row of several point contacts, the formulation regarding the point contact in Equation (1) can also be applied for sliding abrasion by a blade indenter [19].

The coefficient of friction (COF) of the point contact $\mu_{\text {point }}$ from Equation (1) reflects the fact that the whole friction coefficient decreases with the normal load $F_{n}$. It can be seen that the rupturing component depends on the normal load $F_{n}$, while it does not appear on the sliding component. Hence, for a dry surface, an increase of the normal load causes $\mu_{r u p}$ 
to decrease and consequently also the overall friction coefficient, as shown in Figure 3a. It can be observed that at the beginning of the sliding time the friction coefficient for a dry surface is not significantly different, as the sliding component is still dominant.

A wetted or lubricated contact surface reduces the surface roughness and consequently reduces the maximum stress $\sigma_{\max }$, the coefficient of friction for sliding $\mu_{\text {slid }}$ and the overall friction coefficient, as seen in Figure 3b. Moreover, it can be observed that at the beginning of sliding time, the coefficient of friction was significantly lower than in the dry friction situation. This is attributed to the sliding abrasion process, which dominantly occurs on the sliding component than on the rupturing component. Therefore, it can be concluded that the experimental results confirm the analytical approach as presented in Equation (1).

\subsection{Wear Pattern Analysis}

Conventionally, the periodic wear pattern is often associated with the stick-slip contact along sliding abrasion. The length of the wear pattern spacing depends on the stick-slip frequency and sliding velocity [9]. In the fixed load mode as performed in this study, the stick-slip occurrence dominantly occurs in normal direction rather than in tangential direction, especially for high sliding velocities [20]. As previously described, when the surface of the rubber has been abraded, the stick-slip phenomenon more dominantly occurs in oscillation in normal direction than in tangential direction. In that case, the sliding contact yields to a periodic displacement $\Delta x_{n}$ which is the same as the length of the wear pattern spacing. Therefore, with some assumptions, the length of the wear pattern spacing can be calculated using [20]:

$$
\Delta x_{n}=2 \pi V \sqrt{\frac{m_{d w}+m_{i f}}{k_{n}\left(1-\zeta_{n d^{2}}\right)}}
$$

where $\Delta x_{n}$ is the length of the wear pattern spacing, $V$ is the sliding velocity, $m_{d w}$ is the dead mass, $m_{i f}$ is the inertia mass of the indenter system, $k_{n}$ is the normal stiffness of the rubber and $\zeta_{n d}$ is system damping. A detailed derivation and explanation of Equation (2) is given in Appendix A. To simplify the analysis, a proportional parameter $\rho$ is proposed as in [20]:

$$
\rho=\frac{\Delta x_{n}}{\sqrt{m_{d w} g+m_{i f} g}}=\frac{2 \pi V}{\sqrt{k_{n}\left(1-\zeta_{n d}^{2}\right) g}}
$$

where $m_{d w} g$ is the dead weight that represents the static load $F_{n}$ and $m_{i f} g$ is an inertia weight which represents the dynamic load. The dynamic load is derived from the inertia force of the indenter system oscillation [20]. The dynamic load must be constant because of representing the indenter system properties. It can be seen that the right-hand side term represents the material properties of the rubber, except for the sliding velocity $V$. Therefore, when the given sliding velocity $V$ is constant, the proportional parameter $\rho$ should be constant. However, the values of the rubber stiffness and rubber damping are not presented here.

The proportional parameter calculation $\rho$ is presented in Table 2, whereby it is assumed that the inertia force of the indenter system is around $0.16 \mathrm{~N}$. Furthermore, Table 1 shows that the proportional parameter tends to be constant. It indicates that the test results according to Figures 4 and 5 confirm the analytic equations in Equations (2) and (3). Moreover, the wear pattern spacing obtained is longer for a larger deadweight $[10,21,26]$. In short, the wear pattern spacing depends not only on the given deadweight but also on the indenter system properties. 
Table 2. The calculation of proportional parameter $\rho$.

\begin{tabular}{cccc}
\hline $\boldsymbol{F}_{\boldsymbol{n}}(\mathbf{N})$ & $\Delta x_{n}(\mu \mathrm{m})$ & $\Delta x_{n}$ Average $(\mu \mathrm{m})$ & $\rho(\mu \mathrm{m} / \sqrt{N})$ \\
\hline 1.0 & $65-100$ & 83 & 77.1 \\
1.5 & $85-115$ & 100 & 77.6 \\
2.0 & $100-130$ & 115 & 78.2 \\
\hline
\end{tabular}

\section{Conclusions}

This study investigates the tribological responses of rubber abrasion using a blade abrader. This tribological system is often called the line abrasion test. This study uses reinforced Styrene-Butadiene Rubber as a testing specimen. The experiment was carried out using a pin-on-disc tester with various given abrader loads. In addition, the tests were carried out for dry and wetted contact surfaces. The coefficient of friction and wear pattern of the abraded rubber surface were then analyzed.

Analytically, referring to Moore's theory, the average of coefficient of friction (COF) due to the sliding abrasion consists of the sliding and rupturing component. The sliding component is associated with the adhesion and elastic stress of the rubber surface, which does not depend on the indenter load, while the rupturing is associated with the breaking stress of the molecular chain of the rubber, which decreases according to the indenter load. Experimentally, at the beginning of the sliding time, the coefficient of friction (COF) is not significantly influenced by the indenter load. However, for long sliding time, the COF decreases with respect to the blade indenter load and vice versa. At the beginning of the sliding abrasion, the sliding component dominantly occurs over the rupturing component and vice versa for long sliding times. Furthermore, the COF is much lower at the beginning of the sliding abrasion in the case of a wetted surface than in the case of a dry surface. Consequently, it can be concluded that the Moore's theory is qualitatively applicable for the line abrasion test above.

It is clearly shown experimentally and theoretically that the length of the pattern spacing increases as the static load (deadweight) increases. Analytically, the length of the wear pattern spacing depends not only on the static load but also on the dynamic load due to the inertia of the indenter system. It is found that the inertial force of the indenter system is to be constant, therefore the stick-slip theory is applicable for the abrasion test using the blade indenter above.

Author Contributions: Conceptualization, B.S. and M.K.; data curation, B.S.; funding acquisition, B.S.; project administration, R.I. and M.T.; supervision, J. and D.J.S.; validation, B.S.; visualization, B.S. and M.T.; writing-review and editing, B.S. All authors have read and agreed to the published version of the manuscript.

Funding: This research received no external funding.

Institutional Review Board Statement: Not applicable.

Informed Consent Statement: Not applicable.

Data Availability Statement: The data presented in this study are available on request from the corresponding author.

Acknowledgments: This research forms part of the Research Programme of the Dutch Polymer Institute DPI, Project \#782.

Conflicts of Interest: The authors declare no conflict of interest. 


\section{Nomenclature}

$g \quad$ Gravity acceleration $\left[\mathrm{m} / \mathrm{s}^{2}\right]$

$H \quad$ Rubber hardness [MPa]

$K_{1}, K_{2} \quad$ Constants [-]

$k_{n} \quad$ Normal stiffness of the rubber $[\mathrm{N} / \mathrm{m}]$

$F_{n} \quad$ Total normal load [N]

$m_{d w} \quad$ Dead mass [kg]

$m_{\text {if }} \quad$ Inertia mass of the indenter system [kg]

$m_{d w} g \quad$ Dead weight or static load [N]

$m_{i f} g \quad$ Dynamic load or inertia force of the indenter system [N]

$\tan \delta \quad$ Loss factor, depend on the rubber properties [-]

$V \quad$ Sliding velocity $[\mathrm{m} / \mathrm{s}]$

$\Delta x_{n} \quad$ Length of the wear pattern spacing [m]

$\mu_{\text {point }} \quad$ Friction coefficient due to point contact [-]

$\mu_{\text {slid }} \quad$ Coefficient of friction due to sliding [-]

$\mu_{\text {rup }} \quad$ Coefficient of friction due to rupturing [-]

$\rho \quad$ Proportional parameter $\left[\mathrm{m} / \mathrm{N}^{1 / 2}\right]$

$\zeta_{n d} \quad$ Damping factor for abrasion tester [-]

$\sigma_{\max } \quad$ Maximum elastic stress $\left[\mathrm{N} / \mathrm{m}^{2}\right]$

$\sigma_{\text {rup }} \quad$ Breaking stress of the rubber chain $\left[\mathrm{N} / \mathrm{m}^{2}\right]$

$\theta \quad$ Apex angle of cone tip [deg]

\section{Appendix A}

Figure A1 shows the physical model that represents an elastomer surface in contact with a counter surface. It consists of an oscillating elastomer mass $\left(m_{e}\right)$ with stiffness and damping in tangential $\left(k_{t}, c_{t}\right)$ as well as in normal direction $\left(k_{n}, c_{n}\right)$. The acting forces in the contacting surfaces are the driving force $\left(F_{d}\right)$ of the elastomer, the tangential contact force $\left(F_{t}\right)$ and the normal contact force $\left(F_{n}\right)$. During sliding, there are two possibilities of contact interaction between the elastomer surface and the counter surface, namely separation and unification. The separation means no contact between the elastomer surface and the counter surface, see Figure A1a. In this case, the oscillating mass of the elastomer $\left(m_{e}\right)$ oscillates without the mass of the counter surface system $\left(m_{s}\right)$. The unification interaction means that the elastomer surface and the counter surface are unified, and they oscillate together. The unified mass $(M)$ is an aggregate of the oscillating elastomer mass and the inertia mass of the counter surface system $\left(M=m_{e}+m_{s}\right)$, see Figure A1b. Based on Figure A1b, the equation of motion in tangential direction is given in Equation (A1) by involving the tangential force $\left(F_{t}\right)$, sliding velocity $V$ and time $t$. The equation of motion in normal direction is given in Equation (A2).

$$
\begin{gathered}
m_{e} \ddot{x}+c_{t} \dot{x}+k_{t} x=k_{t} V t+c_{t} V-F_{t} \\
M \ddot{y}+c_{n} \dot{y}+k_{n} y=0
\end{gathered}
$$

For a high driving velocity, the elastomer surface dominantly oscillates in the normal direction, meaning that the oscillation in tangential direction can be ignored. It occurs due to tangential stiffness being much higher than normal stiffness. The undamped natural frequency $\omega_{n}$ and damped natural frequency $\omega_{d}$ in the normal oscillation are presented in Equations (A3) and (A4) respectively as follows:

$$
\begin{gathered}
\omega_{n}=\sqrt{\frac{k_{n}}{M}} \\
\omega_{d}=\omega_{n} \sqrt{1-\zeta^{2}}
\end{gathered}
$$




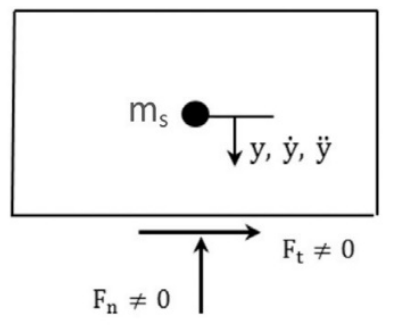

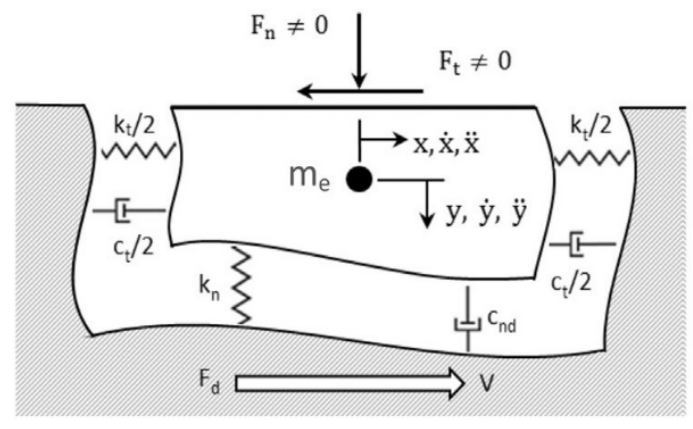

(a)

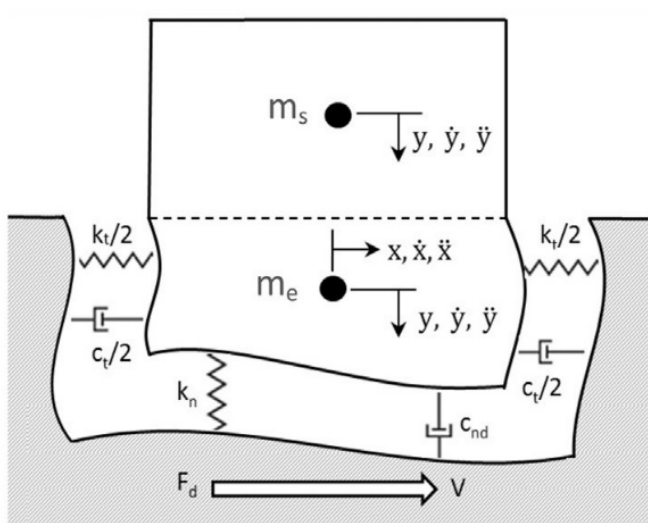

(b)

Figure A1. The interaction during sliding contact between an elastomer surface and a counter surface, (a) separation (b) unification [16].

The normal oscillation period of the system $\left(T_{n}\right)$ can be found from the following equation:

$$
T_{n}=2 \pi \omega_{d}=2 \pi \sqrt{\frac{M}{k_{n}\left(1-\zeta^{2}\right)}}
$$

The periodic displacement $\left(\Delta x_{n}\right)$ in tangential direction due to normal oscillation is:

$$
\Delta x_{n}=V T_{n}=2 \pi V \sqrt{\frac{M}{k_{n}\left(1-\zeta^{2}\right)}}
$$

\section{References}

1. Hokkirigawa, K.; Kato, K. An experimental and theoretical investigation of ploughing, cutting and wedge formation during abrasive wear. Tribol. Int. 1998, 88, 51-57. [CrossRef]

2. Schallamach, A. Abrasion of rubber by a needle. J. Polym. Sci. 1954, 9, 385-404. [CrossRef]

3. Schallamach, A. Friction and abrasion of rubber. Wear 1958, 1, 384-417. [CrossRef]

4. Southern, E.; Thomas, A.C. Studies of rubber abrasion. Rubber Chem. Technol. 1979, 52, 1008-1018. [CrossRef]

5. Bhattacharya, M.; Anil, K.; Bhowmick, A.K. Analysis of wear characteristics of natural rubber nanocomposites. Wear 2010, 269, 152-166. [CrossRef]

6. Gent, A.N.; Pulford, C.T.R. Mechanisms of Rubber Abrasion. J. Appl. Pol. Sci. 1983, 28, 943-960. [CrossRef]

7. Gent, A.N.; Nah, C. Abrasion of rubber by a blade abrader: Effect of blade sharpness and test temperature for selected compounds. Rubber Chem. Technol. 1996, 69, 819. [CrossRef]

8. Fukahori, Y.; Yamazaki, H. Mechanism of rubber abrasion-Part 1: Abrasion pattern formation in natural rubber vulcanizate. Wear 1994, 171, 195-202. [CrossRef]

9. Fukahori, Y.; Yamazaki, H. Mechanism of rubber abrasion—Part 2: General rule in abrasion pattern formation in rubber-like materials. Wear 1994, 178, 109-116. [CrossRef]

10. Fukahori, Y.; Yamazaki, H. Mechanism of rubber abrasion-Part 3: How is friction linked to fracture in rubber abrasion? Wear 1995, 188, 19-26. [CrossRef]

11. Uchiyama, Y.; Ishino, Y. Pattern abrasion mechanism of rubber. Wear 1992, 158, 141-155. [CrossRef]

12. Coveney, C.; Menger, C. Initiation and development of wear of an elastomeric surface by a blade abrader. Wear 1999, 233-235, 702-711. [CrossRef]

13. Grosch, K.A.; Scallamach, A. Relation between abrasion and strength of rubber. Trans. Inst. Rubber Ind. 1965, 41, 80. [CrossRef]

14. Muhr, A.H.; Roberts, A.D. Rubber abrasion and wear. Wear 1992, 158, 213-228. [CrossRef] 
15. Persson, B.N.J. Theory of rubber friction and contact mechanics. J. Chem. Phys. 2001, 115, 8. [CrossRef]

16. Busse, L.; Le Gal, A.; Kluppel, M. Modelling of Dry and Wet Friction of Silica Filled Elastomers on Self-Affine Road Surfaces. LNACM 2009, 51, 1-26.

17. Schallamach, A. Recent advances in knowledge of rubber friction and tire wear. Rubber Chem. Technol. 1968, 41, 209. [CrossRef]

18. Moore, D.F. Principles and Alication of Tribology, 1st ed.; Pergamon Press: Oxford, UK, 1975.

19. Moore, D.F. The Friction and Lubrication of Elastomer, 1st ed.; Pergamon Press: Oxford, UK, 1972.

20. Setiyana, B.; Ismail, R.; Jamari, J.; Schipper, D.J. An analytical study of the wear pattern of an abraded rubber surface: The interaction model. Tribol.-Mater. Surf. Interfaces 2018, 12, 186-192. [CrossRef]

21. Khafidh, M.; Setiyana, B.; Jamari, J.; Masen, M.A.; Schipper, D.J. Understanding the occurrence of a wavy wear track on elastomeric materials. Wear 2018, 412-413, 23-29. [CrossRef]

22. Vieira, T.; Ferreira, R.P.; Kuchiishi, A.K.; Bernucci, L.L.B.; Sinatora, A. Evaluation of friction mechanisms and wear rates on rubber tire materials by low-cost laboratory tests. Wear 2015, 328-329, 556-562. [CrossRef]

23. Rauline, R. Rubber Compound and Tires Based on such a Compound. Google Patents. 1995. Available online: https://patents. google.com/patent/EP0501227A1/en (accessed on 1 August 2021).

24. Hintze, C. Influence of processing on morphology in short aramid fiber reinforced elastomer compounds. J. Appl. Polym. Sci. 2013, 130, 1682-1690. [CrossRef]

25. Setiyana, B.; Ismail, R.; Jamari, J.; Schipper, D.J. Stick-slip behaviour of a viscoelastic flat sliding against a rigid indenter. Tribol. Online 2016, 11, 512-518. [CrossRef]

26. Mané, Z.; Loubet, J.L.; Guerret, C.; Guy, L.; Sanseau, O.; Odoni, L.; Vanel, L.; Long, D.R.; Sotta, P. A new rotary tribometer to study the wear of reinforced rubber materials. Wear 2013, 306, 149-160. [CrossRef] 